\title{
Capital social e redes sociais como alternativa para análise de políticas públicas de educação: o caso de Icapuí-CE*
}

Rafael D'Almeida Martins **

Gabriela Spanghero Lotta***

\section{Resumo}

0 objetivo deste artigo é analisar o processo de elaboração da política de universalização do ensino fundamental do município de Icapui, $C E_{1}$ com base nos conceitos de capital social e redes sociais. A partir desses conceitos e por meio de uma perspectiva histórica, estudam-se as ações da Secretaria de Educação como um caso de política pública de sucesso, por meio de gestão participativa, democrática e descentralizada, fortemente embasada em relações sociais entre a comunidade e o poder público que foram beneficiadas pela existência de níveis elevados de engajamento cívico e laços comunitários fortes, originados durante o processo de emancipação política do municipio. Mostramos que esse contexto sócio-histórico e a constituição de redes sociais foram suficientes para criar e mobilizar o capital social existente na comunidade e, assim, contribuir para o desenvolvimento de ações orientadas a transformação social.

Palavras-chave: Capital social. Redes sociais. Política municipal de educação. Icapuí.

\section{Social capital and social networks as alternatives or educational public policy analysis: the Icapui-CE case Abstract}

This paper aims to analyze the process of implementation and universalization

\footnotetext{
Pesquisa realizada pelos autores durante o mês de Janeiro e Fevereiro de 2003 no município de IcapuíCE. A pesquisa foi financiada pelo Centro de Estudos em Administração Pública e Governo da Fundação Getúlio Vargas de São Paulo (CEAPG/FGV-EAESP). Esse artigo amplia reflexões anteriores dos autores apresentadas no I Encontro Nacional de Administração Pública e Governança (EnAPG), da Associação Nacional de Pós-Graduação e Pesquisa em Administração (ANPAD), Rio de Janeiro, e no 4th International Meeting of the Iberoamerican Academy of Management, Lisboa.

-. Doutorando em Ambiente e Sociedade, Núcleo de Estudos e Pesquisas Ambientais (NEPAM), Universidade Estadual de Campinas (UNICAMP); Bolsista CAPES. E-mail: rdamartins@gmail.com

… Doutora em Ciência Política, Faculdade de Filosofia, Letras e Ciências Humanas, Universidade de São Paulo (FFLCH-USP). E-mail: gabriela.lotta@gmail.com
} 
of the elementary education policy in the municipality of Icapui-CE, based on the concepts of social capital and social networks. From these concepts, we studied the actions of the Secretary of Education as a case of successful public policy making through participatory management, democratic and decentralized, heavily based on social relationships between the community and the public who have been benefited by the existence of high levels of civic engagement and strong community ties arising during the process of political emancipation of the municipality. It shows that the socio-historical context and the social networks were sufficient to create and mobilize the social capital existing in the community and thus able to develop actions for social transformation.

Keywords: Social capital. Social networks. Municipal policy of education. Icapui

\section{Capital social $y$ redes sociales como alternativas para el análisis de politicas públicas de educación: el caso de Icapui-CE (CE: CEARÁ - Provincia brasileña) \\ Resumen}

El objetivo de este trabajo es analizar el proceso de elaboración de la política de universalización de la Educación Primaria en la ciudad de Icapuí-CE (CE: CEARÁ Provincia brasileña), basado en los conceptos de capital social y redes sociales. $A$ partir de dichos conceptos y a través del uso de una perspectiva histórica, se estudiaron las acciones de la Dirección de Educación como un caso de políticas públicas que tuvo éxito, realizado por medio de gestión participativa, democrática y descentralizada, fuertemente basado en relaciones sociales entre la comunidad y el poder público beneficiadas por la existencia de niveles elevados de participación cívica y fuertes lazos comunitarios originados durante el proceso de emancipación política del municipio. Mostramos que ese contexto socio-histórico y la constitución de redes sociales fueron suficientes para crear y movilizar el capital social existente en la comunidad y, así, contribuir para el desarrollo de acciones orientadas hacia la transformación social.

Palabras clave: Capital social. Redes sociales. Política municipal de Educación. Icapuí

\section{Introdução}

0 presente artigo avalia o processo de elaboração e implementação da política pública de universalização do ensino fundamental no município de Icapuí, Ceará, tomando como base a contribuição da abordagem de capital social e redes sociais. Sabe-se que as redes sociais podem melhorar a implementação de políticas públicas, tornando-as mais efetivas (TROTTER, 1999; MARQUES, 2009), inclusive ajus- 
tando-as a aspectos locais e culturais, como em casos de politicas de saúde (LOTTA, 2006). Análises recentes ressaltam a necessidade de incorporar a dinâmica municipal na avaliação da política educacional (GOUVEIA, 2009). Entretanto, apesar de relevantes, as abordagens neoinstitucionalistas e de redes sociais são pouco debatidas nos estudos brasileiros sobre políticas de educação.

Assim, o objetivo deste artigo é contribuir com esse debate analisando as ações da Secretaria de Educação do município de Icapuí a partir dessas abordagens em perspectiva histórica. Icapuí pode ser entendido como um caso de política pública de sucesso com gestão participativa, democrática e descentralizada, fortemente embasada em relações sociais entre comunidade e o poder público. Do resultado da conjunção entre capital social e a existência de redes sociais surgiu uma iniciativa de referência para o enfrentamento do analfabetismo e da exclusão social.

Ao longo dos 25 anos de emancipação, o município tem sido modelo na gestão de políticas públicas. Obteve resultados expressivos em relação a municípios do mesmo porte, aumento da qualidade de vida e melhoria acentuada dos indicadores sociais (LOTTA; MARTINS, 2003). Além disso, foi o primeiro municipio brasileiro a universalizar o ensino fundamental e, como consequência de suas ações, ganhou diversos prêmios, como Prefeito Amigo da Criança (Fundação Abrinq), Município Aprovado (UNICEF), Programa Gestão Pública e Cidadania (Fundação Getúlio Vargas/EAESP, Banco Nacional de Desenvolvimento Econômico e Social e Fundação Ford), entre outros. Destacam-se também as ações realizadas na área de saúde que, assim como a área de educação, obtiveram reconhecimento nacional (LOTA, 2006).

No presente artigo, analisamos como os bons resultados alcançados pelo município decorrem diretamente da formação e mobilização de capital social e da existência de redes sociais em momentos históricos determinados, que são apresentados e discutidos no estudo de caso.

0 artigo está dividido em duas partes, tirando a introdução e a conclusão. Na primeira parte, apresenta-se uma breve revisão bibliográfica dos conceitos de capital social debatidos por Putnam $(1993,1996)$ e Evans $(1996 a, 1996 b)$ e dos conceitos institucionalistas de redes sociais (MARQUES, 1999, 2003). Na segunda parte, analisa-se a política pública de educação de Icapuí, discutindo os três momentos históricos que foram fundamentais para a formação e mobilização do capital social e constituição da rede social em questão, como forma de uma ação coletiva voltada para a transformação social.

\section{Nota metodológica}

Em termos metodológicos, realizou-se uma revisão da literatura sobre os conceitos de capital social e redes sociais. Em seguida, foram utilizados dados referentes até o ano de 2004, coletados em pesquisa de campo etnográfica, englobando as 
seguintes atividades: (1) visita ao município; (2) observação participante de reuniões dos órgãos gestores; (3) entrevistas com membros de diversas secretarias envolvidas na política de educação; (4) entrevista com representantes da população local e pessoas ligadas às instituições (empresas, institutos de pesquisa) envolvidas na política pública; (5) entrevista com profissionais e acadêmicos ligados à história das experiências; (6) análise de arquivos, dados, jornais locais e regionais. Também foram usados dados secundários para fundamentação da análise.

Em posse dos dados e materiais, realizou-se uma nova análise dos resultados encontrados em perspectiva com a teoria, resultando, por fim, na sistematização e análise geral dos dados levantados.

\section{O debate sobre Capital Social}

0 conceito de capital social vem crescentemente sendo empregado por pesquisadores e teóricos e tem sua origem nos trabalhos seminais de Bourdieu (1980; 1985) e James Coleman (1988; 1990). Surgiu como um importante elemento para o entendimento e a compreensão do funcionamento das relações humanas e dos arranjos sociais que são estabelecidos em favor da disputa pelo equilibrio entre igualdade e liberdade (SANTOS, 2003, p. 20), buscando enfrentar o problema da ação coletiva nas relações sociais.

As explicações da teoria da ação coletiva partem do pressuposto de que os indivíduos são atores intencionais que perseguem objetivos específicos. Para Olson (1999), os indivíduos não farão parte de grupos que lutam por um bem público a menos que haja coação ou sejam estimulados mediante algum bem privado. Assim, estabelecia-se o problema da ação coletiva ou o problema do free rider (efeito carona). Quando alguém conta com a possibilidade de beneficiar-se da ação coletiva dos demais, sem sofrer os custos da participação, há um grande incentivo para se comportar isoladamente. Pode-se dizer, portanto, que o problema da ação coletiva aparece quando o interesse privado sobrepõe-se à obtenção do bem público.

A hipótese levantada por Coleman (1990) é de que existe uma relação de complementação direta entre capital econômico (e.g. infraestrutura e financiamento), capital humano (e.g. educação) e capital social (e.g. relações de confiança). A junção entre o capital econômico e o capital humano será potencializada à medida que as relações de confiança e cooperação aumentem na comunidade (ABU-EL-HAJ, 1999, p. 68). Desta forma, em comunidades, onde o nivel educacional e os recursos financeiros disponiveis são constantes, o possivel diferencial de desempenho ou desenvolvimento de seus integrantes pode ser explicado pelos laços de confiança estabelecidos entre os membros da comunidade a qual permite mobilização social coletiva e a otimização dos recursos individuais existentes. 


\section{Duas abordagens}

Neste trabalho apresentaremos as abordagens de capital social propostas por dois autores importantes no debate internacional sobre o tema: o culturalismo de Robert Putnam e a abordagem neoinstitucionalista de Peter Evans.

\section{O culturalismo em Putnam}

Robert Putnam $(1993 ;$ 1996) partiu do tema da democracia dentro de um contexto sociocultural específico para analisar as mudanças administrativas na Itália. 0 estudo apresenta que a complementação entre as ações institucionais de caráter público e as ações coletivas aumentam e fortalecem o engajamento cívico. Se, por um lado as experiências de mobilização coletiva acumulam capital social que derivam em grande parte, dos laços de confiança e cooperação estabelecidos entre os cidadãos. Por outro, um governo composto por elites reformistas em posse de uma agenda progressista e que pretendem implementar mudanças sociais determinadas por normas transparentes, que regulem a interação entre os interesses organizados, facilita a propagação de uma vida pública ativa e dinâmica. Assim, segundo Putnam (1996), a sinergia entre público e privado amplia a confiança e a transparência, permitindo a implementação de políticas públicas que promovam transformação social e aumentem o bem-estar (ABU-EL-HA, 1999, p. 69).

Esta teoria apoia-se em uma inclinação de especificidades culturais para explicar a formação de laços de confiança. Assim, localidades com histórico de práticas associativistas ou engajamento cívico e político determinam a existência de capital social. Comunidades baseadas no associativismo, com normas transparentes e redes de solidariedade (horizontal) devem apresentar níveis elevados de engajamento cívico e organização comunitária que contribuem para um alto desempenho econômico, garantindo níveis altos de bem-estar entre seus cidadãos, produzindo estabilidade econômica. Assim, pode-se dizer que há uma relação direta entre o nível de engajamento cívico e as prosperidades econômica, social e política. Em contraposição, a ausência ou níveis inferiores de laços de confianças não promovem o engajamento civico necessário e atuam como barreiras para a ação coletiva.

A partir de seu estudo, Putnam $(1993,1996)$ faz duas grandes generalizações. A primeira estabelece como a condição principal na determinação do nível de associativismo o contexto histórico-cultural, já que o processo de acúmulo de laços comunitários e engajamento cívico para práticas associativistas é lento e pressupõe uma cultura específica de determinadas comunidades. A segunda afirma a importância das instituições públicas na indução do associativismo. Assim, as ações politicas governamentais também seriam determinantes para configuração do tipo e da intensidade da ação coletiva. Governos dirigidos por elites politicas reformistas melhorariam a qualidade das políticas públicas e aumentariam o desempenho institucional do local. 


\section{0 neoinstitucionalismo em Peter Evans}

Peter Evans tem uma posição crítica em relação ao trabalho de Putnam, sobretudo de caráter metodológico, à medida que Putnam reafirma a separação clássica entre as esferas pública e privada. Esta separação do Estado seria a base de sua autonomia em relação à sociedade e ao cotidiano político da localidade. Evans (1996a, 1996b) defende que o suposto distanciamento do Estado em relação à sociedade não assegura seu papel de potencial transformador social e tampouco garante sua autonomia.

Os neoinstitucionalistas também rejeitam a relação direta entre o contexto sociocultural histórico com a suposta formação de laços de confiança e o nível de engajamento cívico estabelecido pela obra de Putnam - que assume uma continuidade linear das formas originais de organização da comunidade (ABU-EL-HAJ, 1999, p. 71). Sendo verdade essas generalizações, a ausência de um contexto cultural favorável condenaria diversos países e localidades do mundo em desenvolvimento a regimes oligárquicos, ao atraso social e ao subdesenvolvimento econômico.

Segundo a corrente neoinstitucionalista, a ausência de laços de confiança, de práticas associativistas e níveis baixos de engajamento político são dados por ações políticas que impedem seu desenvolvimento. A ideia decorre do pressuposto de que as instituições públicas detêm o monopólio da força (coerção social) e a capacidade única de mobilização e organização social. 0 Estado moderno seria a arena principal para a convergência das demandas sociais (EVANS, 1996b) que determinariam o êxito das mobilizações sociais. As instituições públicas e seu poder de intervenção seriam responsáveis por dar forma à ação coletiva e à interação social do local. Dessa maneira, observa-se a mudança no papel do Estado de um regulador da ação e da interação social para o Estado como mobilizador de capital social e responsável pelo ativismo político que dariam as bases institucionais para a mobilização, ou não, das iniciativas coletivas.

\section{Neoinstitucionalismo e redes sociais}

0 conceito de redes sociais aqui apresentado baseia-se em uma abordagem neoinstitucionalista. Para tanto, faremos primeiramente uma contextualização do institucionalismo na ciência política contemporânea. A ciência política contemporânea se desenvolve basicamente em três linhas de análise: pluralismo, neomarxismo e neoinstitucionalismo.

\section{Pluralistas}

Para os pluralistas, está presente a noção de que existe uma sociedade plural e de que a competição entre os diversos grupos de interesse produziria bons resultados para a democracia, através do confronto mútuo entre as diferentes organizações sociais. Assim, quem governa seriam os "partidos políticos, organizações de galvanização de interesse e canalização de participação" (MARQUES, 2003, p. 31). 
Os pluralistas ainda avançam nessa discussão, afirmando que o Estado seria uma arena, desprovida de conteúdo, a ser ocupada por diversos grupos de interesse em constantes disputas (DAHL, 1982). Esse é o ponto principal de discussão com a segunda corrente, os neomarxistas, para quem o Estado seria um Estado burguês, ocupado por uma classe social definida economicamente.

Os pluralistas ainda tratam da ação social, afirmando que a sociedade é composta de indivíduos livres em um sistema de governo liberal. A política é vista, portanto, como ação de indivíduos livres para defender sua liberdade. Assim, a autonomia dos indivíduos está justamente na sua capacidade de exercer ações - defendendo seus interesses e agindo conforme suas necessidades e vontades.

\section{Neomarxistas}

Para os neomarxistas, o Estado não é fruto da vontade dos individuos livres, mas sim o resultado do desenvolvimento de forças produtivas. Assim, o Estado em si é um Estado burguês, instrumento de dominação da burguesia e que defenderia os interesses do capital a fim de manter a dominação da burguesia sobre o proletariado. Dessa forma, a emancipação social só se daria a partir da luta de classes e da aniquilação desse Estado'. Marx (1969), no entanto, retomou sua teoria e a redefiniu-a no clássico "18 de Brumário de Luis Bonaparte". Nesse texto, percebe-se que o Estado, antes concebido unicamente como um aparato de dominação burguesa, pode, por vezes, ser autônomo em relação às classes. No entanto, essa autonomia é relativa, à medida que os interesses são realizados, mesmo que indiretamente, em favor da burguesia.

Poulantzas (1977) retoma esse conceito de autonomia relativa, identificando diversas facções da burguesia e afirmando que o Estado seria controlado pelas facções hegemônicas em determinado momento histórico. Assim, o Estado, com a função de organizar os capitalistas autônomos como classe e desorganizar os trabalhadores, seria uma arena de lutas e conflitos entre os diversos atores. Essa ideia reforça a noção de autonomia do Estado, que pode defender os interesses de diferentes grupos de classe.

Embora as correntes pluralista e neomarxista observem a sociedade - diferentemente dos neoinstitucionalistas que olham para as instituições - há uma grande diferença na forma de observação de ambas as correntes. Para os pluralistas, a sociedade passa por individuos agregados em grupos. Não há dominação estrutural da burguesia, há sim vários grupos e um se sobrepõe ao outro assumindo o Estado por um período determinado. 0 Estado é uma caixa vazia de interesses e varia conforme o grupo que 0 assuma. Já para os marxistas, a sociedade é de classes. Todas as ações do Estado, portanto, são estruturalmente políticas para preservação da ordem burguesa.

Na medida em que os marxistas buscam o fim do Estado, isso os diferencia dos institucionalistas e de outros autores que pensam no poder das instituições para controlar o Estado. 


\section{Neoinstitucionalistas}

A terceira corrente, dos neoinstitucionalistas, passa de uma análise societária para uma análise de instituições. Para autores dessa corrente, o Estado não seria subordinável a grupos de interesse - a própria organização estatal e a burocracia apresentariam interesses próprios diversos de quaisquer outros agentes (MARQUES, 2003, p. 41) e, por deterem o poder do Estado e a cadeia de ação, as burocracias poderiam inclusive se transformar no mais importante autor no processo de decisão de políticas públicas.

Para os institucionalistas, são as instituições que moldam a ação dos indivíduos, através das regras, normas e constrangimentos. Para esses autores, ainda, as instituições têm o objetivo de reduzir incertezas, criando estruturas estáveis para a interação humana.

Os neoinstitucionalistas podem ser divididos em duas correntes: os da rational choice e os históricos. Para os primeiros, que têm sua base nos neoclássicos, todas as ações seriam delimitadas por escolhas racionais. As ações, portanto, seriam sempre guiadas para a maximização do resultado, de forma que as estruturas determinariam as preferências. Para esses autores, ainda, as preferências seriam sempre exógenas e o risco de transação (path dependence) é sempre alto o suficiente para não permitir aos jogadores voltarem atrás (LEVI, 1997).

Para a segunda corrente, os neoinstitucionalistas históricos, a análise tenta ser um contraponto entre a observação apenas das instituições e a observação apenas societária. Assim, eles explicam as escolhas como resultado de interesses conflitantes em que há alguns atores mais beneficiados que outros. Esses autores afirmam, portanto, que os atores sociais não são maximizadores egoístas e as instituições não somente constrangem interações, mas cultuam conformação de preferência, sendo as preferências endógenas.

A grande crítica aos neoinstitucionalistas está no determinismo de suas explicações. À medida que colocam as ações pautadas pela maximização do resultado e se utilizam do conceito de path dependence, a teoria passa a basear-se em uma visão determinada das ações. Assim, eles ignoram "as forças políticas que, de fato, determinam os rumos da intervenção institucional" (ABU-EL-HAJ, 1999, p. 77).

\section{Redes Sociais na perspectiva neoinstitucionalista}

É dentro da corrente neoinstitucionalista que podemos encontrar a utilização de redes como método de análise de políticas públicas. De acordo com Marques (2003, 2007), as políticas públicas são definidas pela interação entre atores no interior dos ambientes institucionais e relacionais presentes nas comunidades políticas. As dinâmicas políticas são, portanto, resultado dessas interações, tendo em conta os constrangimentos das instituições e das redes de relações pessoais e institucionais presentes. Assim, "o efeito das redes de relações entre indivíduos e organizações no 
interior das comunidades politicas estatais é similar ao das instituições, estruturando o campo e influenciando resultados, estratégias e formando e alterando preferências" (MARQUES, 2003, p. 52).

A metodologia de análise a partir das redes que foi adotada por Marques (2003, 2009), permite identificar os padrões de relacionamento entre atores em uma ação social. A rede social, para o autor, é um campo existente em um dado período, estruturado por vínculos entre indivíduos, grupos e organizações que têm naturezas diversas. A rede, portanto, pode ser vista como composta de diversas camadas, cada qual associada a um tipo de relação e a um dado período (MARQUES, 2007). 0 caráter institucional da rede se dá à medida que elas moldam as ações e estratégias dos atores, dependendo de sua posição, bem como ajudam a construir as preferências, os projetos e as visões de mundo. A rede se torna como uma instituição, portanto, sendo uma "estrutura do campo no interior do qual estão imersos os atores sociais e políticos relevantes em cada situação concreta" (MAROUES, 1999, p. 46).

\section{0 caso de Icapuí}

\section{0 município}

Icapuí é um pequeno município do litoral do Estado do Ceará que faz fronteira com o Estado do Rio Grande do Norte. A população, de cerca de 19.385 habitantes $^{2}$, distribui-se entre a zona urbana (70\%) e rural (30\%) (LOTTA; MARTINS, 2003). A base econômica do município é o setor primário, tendo como principais produtos a lagosta, o sal marinho, as culturas de caju e de coco e, mais recentemente, o petróleo. A pesca é o setor de maior importância na economia do município e também o que emprega mais pessoas. Do total de 2877 familias, 1382 estão vinculadas à pesca direta ou indiretamente (LOTTA; MARTINS, 2003).

Para efeitos de análise, agrupamos a história do município em três períodos históricos conforme o Quadro 1, baseando-se no trabalho de Lotta e Martins (2003).

\begin{tabular}{|l|l|l|}
\hline Período & Décadas & Características \\
\hline a) Antecedentes & $1930-1980$ & $\begin{array}{l}\text { Distrito de Aracati. Início do processo de } \\
\text { luta pela emancipação. Retrocesso por parte } \\
\text { das oligarquias locais e do golpe militar de 1964 }\end{array}$ \\
\hline b) A Luta pela Emancipação & $1980-1985$ & $\begin{array}{l}\text { Mobilização e organização dos atores e } \\
\text { instituições para a emancipação do municipio. }\end{array}$ \\
\hline $\begin{array}{l}\text { c) Administração Democrática } \\
\text { Popular }\end{array}$ & $1986-2004$ & $\begin{array}{l}\text { Políticas públicas inovadoras e democráticas } \\
\text { baseadas em gestão descentralizada } \\
\text { e forte participação popular. }\end{array}$ \\
\hline
\end{tabular}

Quadro 1 - Períodos históricos do Município de Icapuí (1930-2004). Fonte: Adaptado de Lotta e Martins (2003).

2 Estimativas disponíveis no sítio do Instituto Brasileiro de Geografia e Estatística (IBGE), Cidades. Consulta feita em 04/01/2010. 


\section{Marco de análise: os três momentos históricos}

\section{a) Antecedentes (1930-1980)}

Durante grande parte do século XX, Icapui foi um distrito do município vizinho Aracati. No entanto, as diversas lutas pela emancipação do município foram ocorrendo ao longo das décadas. 0 processo começou em 1938, mas se tornou maior a partir de 1956, quando o distrito conseguiu organizar-se politicamente e obter a criação do município em 1959. A votação da lei que regulamentaria este ato fora, no entanto, atrasada por manobra das forças da oligarquia local contrária à independência do município, o que transferiu as eleições municipais para 1966. Entretanto, o golpe militar de 1964, ocorrido no meio desse período, atrasou por mais duas décadas o sonho da independência. Durante todo este período, no entanto, foi-se formando uma identidade entre os habitantes do então distrito de Icapui voltados para a luta política pela emancipação.

Robert Putnam (1996), em seu estudo sobre o desenvolvimento político das regiões da Itália, estabeleceu uma relação direta entre o nível de engajamento cívico da comunidade e a qualidade de sua governança (COSTA, 2003, p. 155). A explicação de um desempenho econômico e institucional superior no Norte da Itália está atrelada nas instituições e organizações que datam de mil anos atrás, com a presença de associativismo (horizontal) e alto nível de participação cívica. Desta forma, o capital social está relacionado aos laços de confiança mútua, redes estabelecidas de cooperação, mecanismos comunitários de coerção e comportamento para a solução de problemas dependentes da ação coletiva.

Na tentativa de mensurarmos a qualidade de capital social presente na experiência relatada de Icapuí, adota-se neste artigo uma concepção de capital social geral que contém as seguintes caracteristicas: (a) relações de participação, cooperação e confiança que são responsáveis pela criação e/ou fortalecimento do capital social; (b) o capital social não é o único responsável pelo desenvolvimento de uma comunidade, já que este também depende das várias combinações de outras condições; (c) a participação da comunidade é elemento fundamental do capital social que pressupõe formas democráticas de governo, sendo o Estado responsável por criar a cultura democrática e a transparência nos assuntos públicos (COSTA, 2003, p. 157).

No caso de lcapuí, não só o início das políticas públicas de caráter universalistas na área de educação, mas também as da área de saúde, estão diretamente relacionadas com o processo de emancipação. Adota-se, a partir deste ponto, o conceito de capital social formulado e proposto por Putnam (1996) por considerar-se que o caminho percorrido pelos diversos membros da comunidade demonstra elevados niveis de engajamento cívico (civismo), intensidade de vida comunitária e a construção de laços fortes de confiança mútua entre atores sociais importantes ao longo dos anos. Estes fatores foram essenciais para a constituição de redes sociais de sustentação de um projeto político que será analisado nas partes seguintes deste artigo. 
A ideia da emancipação do município de Aracati e a consequente luta pela separação foi, sem dúvida, um dos elementos histórico-culturais que aglutinou as forças sociais presentes na comunidade de Icapuí. É durante esses anos que, do ponto de vista sociológico, o capital social foi sendo formado. Como fator impulsionador da formação desse capital social tem-se uma identidade cultural comum entre uma parcela dos habitantes do então distrito de Icapuí que, além do desejo de criarem um município, compartilhavam do sentimento de abandono e descaso no tocante à provisão dos serviços públicos por parte do município de Aracati.

Os sérios problemas sociais e uma alternativa politica audaciosa e tentadora eram os ingredientes principais que reforçavam a identidade cultural do local e davam a sensação de pertencimento comunitário, elevando o nível de engajamento cívico e, consequentemente, o estoque de capital social na sociedade. Esse foi um processo lento, que pressupôs características culturais particulares da localidade e durou algumas décadas, até o momento em que as redes sociais já estavam consolidadas e os laços de confiança entre os atores políticos formados.

Neste momento histórico de Icapuí, podemos aplicar a análise de redes sociais, nos moldes do que foi proposto por Marques (1999, 2003). 0 autor entende a rede social como o campo presente em determinado momento, estruturado por vínculos entre indivíduos, grupos e organizações constituídas ao longo de um periodo (MARQUES, 1999, p. 46). Temos, assim, em Icapuí, a constituição de uma rede durante o século XX, estruturada por relações entre algumas pessoas da oligarquia local, juntamente com lideranças comunitárias, em torno de um objetivo comum: a luta pela emancipação. Embora institucionalmente ainda fraca, essa rede foi a responsável por iniciar o processo emancipatório que quase conseguiu, nos anos 1950/1960, a independência formal do município em relação a Aracati. Essa mesma rede, embora sofrendo algumas modificações no tempo e com alguns pontos de ligação trocados, consolidou um aparato institucional (MARQUES, 2003) capaz de manter viva a batalha pela emancipação, como poderemos ver no segundo momento histórico.

\section{b) A luta pela emancipação (1980-1985)}

No início dos anos 1980, um grupo de jovens de Icapui, provenientes da oligarquia local, e que tinham saído da região para estudar e realizar o ensino superior na capital do estado, Fortaleza, passou a encontrar-se regularmente durante o período de férias escolares. Retomando a questão da emancipação, o grupo decidiu tomar algumas ações para continuar a luta pela emancipação. Fundaram, então, uma associação de jovens e estreitaram o contato com a população local, tentando mobilizála para que reinvidicasse a emancipação.

Durante esse mesmo periodo, a Igreja Católica desenvolvia uma ação social na região, buscando organizar as comunidades e suprir o descaso da administração de Aracati que tinha a região de Icapui apenas como um curral eleitoral (ALMEIDA, 1993; LOTA; 
MARTINS, 2003). Assim, o trabalho da Igreja foi conseguindo mobilizar e capacitar lideranças comunitárias nas diversas comunidades locais. Formou-se, assim, um grupo coeso e determinado a lutar pela emancipação, composto pela associação de jovens, juntamente com antigas lideranças do movimento emancipatório dos anos 1950, organizações estudantis, Igreja Católica, líderes comunitários e políticos contrários a Aracati.

Em 1982, o líder do grupo de jovens conseguiu ser eleito vereador de Aracati, com a terceira maior votação, comprometido a levar a questão da emancipação à Câmara dos Vereadores de Aracati. 0 movimento emancipatório foi, pouco a pouco, crescendo nos anos seguintes e conquistando novas lideranças. Em 1984, Icapuí conseguiu realizar um plebiscito pela emancipação. 0 "sim" venceu o "não". A primeira eleição municipal foi marcada para o ano seguinte, coincidindo com as eleições gerais do Estado do Ceará.

Neste segundo momento histórico também podemos ver a presença do capital social formado e acumulado no período anterior. Este capital social, no entanto, diferentemente do anterior - que tinha um caráter histórico e culturalista - apresenta características de natureza institucionalistas.

Para esta análise, utiliza-se a perspectiva de capital social apresentada por Evans (1996a). Para a execução de políticas sociais, o autor ressalta a importância de um agente mobilizador, dotado de forte engajamento político e capaz de criar um círculo virtuoso. 0 que difere a perspectiva do autor desta análise em questão é que para Evans esse agente é o Estado. No caso de Icapuí, no entanto, a criação e mobilização do capital social, como pode-se ver no que foi apresentado não poderia ter sido realizada pelo Estado que, inclusive, era contrário ao projeto emancipatório. Assim, essa mobilização se deve a diversas instituições e atores da sociedade civil que se juntaram em torno de um projeto comum: a associação dos jovens, a Igreja Católica, os grupos comunitários e a rede de relações existentes então - que pode ser vista, da perspectiva neoinstitucionalista de rede, como uma instituição.

Neste segundo momento histórico também pode-se ver retomada a rede social. Segundo Marques (2003, p. 156), de maneira geral as redes de relações apresentam dinâmicas marcadas por uma forte dependência da trajetória percorrida. Assim, ela é composta, em um determinado momento, por uma superposição da rede herdada de períodos anteriores com novos indivíduos e vínculos, subtraídos dos vínculos e indivíduos que dela saíram. Se, no caso de Icapui, ao longo dos anos de luta pela emancipação já se formava uma rede, neste momento essa rede é estruturada e consolidada, agregando a ela os diversos atores de Icapui que buscavam a emancipação. A rede, portanto, se via agora composta de membros da oligarquia (grupo de jovens) e lideranças comunitárias, todos batalhando por um projeto comum. 
Ainda segundo Marques (2003), as políticas públicas são definidas pela interação entre atores nos ambientes institucionais e relacionais presentes nas comunidades. As dinâmicas políticas são, portanto, resultado das interações entre os componentes da rede. Isso pode ser facilmente comprovado no caso de Icapuí. À medida que a rede foi estruturada e conseguiu criar laços fortes, as dinâmicas politicas foram acontecendo.

\section{c) Administração Democrática Popular (1986-2004)}

A equipe de governo formada, quando assumiu a prefeitura, tinha como base 0 grupo de jovens que se mobilizara pela emancipação e tentava compensar sua inexperiência com grande disposição e voluntarismo (ALMEIDA, 1993, p. 10). 0 momento político do Ceará havia concentrado a grande maioria de quadros progressistas e capacitados na administração de Fortaleza, capital do Estado. Todas mobilizações e atividades desenvolvidas na região durante o período anterior à emancipação, seja por parte dos pioneiros na ideia emancipatória, seja as ações da Igreja Católica e mais recentemente na composição do grupo de jovens ocupando os quadros administrativos da nova prefeitura, construíram redes sociais de cooperação sólidas que foram essenciais para dar suporte às ações dos primeiros anos de mandato.

Já na primeira administração, o municipio enfrentou diversas dificuldades buscando implementar uma gestão inovadora com novos modelos políticos e administrativos de enfrentamento aos problemas sociais e atendimento às demandas da população. Alto índice de mortalidade infantil, falta de leitos hospitalares, 70\% de analfabetismo, elevado número de professores leigos e poucas escolas eram apenas alguns exemplos dos grandes desafios a serem enfrentados pelo município.

Para enfrentá-los, as principais ações iniciais foram: participação popular, transparência administrativa, democratização e universalização dos serviços públicos, principalmente de educação e saúde. Até 2004, Icapuí passou por quatro gestões municipais seguidas, todas conduzidas pelo grupo que liderara a emancipação. A reversão do quadro social, a universalização da educação e do acesso a direitos, transparência e participação tornaram-se marcas desse período de administrações.

Procurando estabelecer uma alternativa metodológica neoinstitucionalista à visão histórico-cultural de Putnam, Evans (1996a; 1996b) colocou o potencial do Estado, na forma de sua burocracia, na formação e mobilização do capital social. O Estado passaria de uma função ação reguladora da dinâmica social para a de indutor e mobilizador do capital social, provocando sinergia entre Estado e sociedade civil, aumentando o desempenho institucional do conjunto das combinações (ABU-EL-HAJ, 1999; COSTA, 2003). Para Evans, redes de engajamento cívico entre membros de uma comunidade podem ser induzidos por instituições públicas. Em ambientes com laços fortes de confiança mútua, a sinergia entre Estado e sociedade provocaria uma onda de mudança institucional. 0 funcionamento da sinergia estaria vinculado à intensidade do engajamento das instituições públicas no processo. 
A perspectiva de análise de Peter Evans serve como alternativa para entender este momento específico do caso de Icapuí, à medida que o autor ressalta a importância do Estado como agente indutor, dotado de forte engajamento político e capaz de mobilizar capital social em torno da melhora de desempenho das políticas públicas. No estudo de caso, a movimentação em torno da luta pela emancipação levou o Estado a ter um papel indutor e mobilizador de capital social na comunidade.

\section{Ações na Educação}

Com base na realidade social de Icapuí, a nova administração municipal decidiu ter, como prioridade, a garantia da universalização do ensino. Para tanto, ainda em 1986, foi colocado como meta que no prazo de um ano fossem garantidas vagas nas escolas para todas as crianças do município. Primeiramente, foi feita uma ampla mobilização popular por meio de um processo de estímulo à participação e ao envolvimento da comunidade, aproveitando a mobilização social decorrente da emancipação para envolver a sociedade na administração do município.

Passando de casa em casa, foi-se criando um grupo de apoiadores, ao mesmo tempo em que se consolidava a ideia de que o poder estava sendo distribuido e compartilhado. 0 envolvimento da população na implementação da universalização do ensino, conseguindo professores locais e se conscientizando da necessidade de educação foi alto. Após garantir o envolvimento da população, foram recrutados como professores pessoas que tivessem, pelo menos, o ensino fundamental, considerado suficiente para alfabetizar as crianças dado o quadro de carência do município.

A estrutura das salas de aula também foi improvisada. A população cedeu espaços como Igrejas ou até mesmo um pé de cajueiro, sob o qual as crianças passaram a ser alfabetizadas. Os resultados do primeiro ano já foram satisfatórios, conseguindo-se aumentar de 17 para 59 o número de salas de aula e de 690 para 3.059 as vagas disponiveis. Para as crianças que viviam na área rural ou que não tinham escolas próximas, a educação foi garantida por meio do transporte escolar.

Paralelo a isso, os professores "improvisados" passaram a receber formação e capacitação com base na pedagogia de Paulo Freire (1987). Assim, a pedagogia adotava a alfabetização de jovens e adultos para poderem entrar e participar da sociedade e de sua transformação. Com base nisso, foram formados os Círculos de Cultura e Aprendizagem, com o objetivo de diminuir os índices de analfabetismo entre jovens e adultos.

Após o primeiro ano de mandato veio a necessidade de vagas no ensino médio. Assim, adotou-se como meta garantir o acesso ao ensino médio ainda no segundo ano de mandato. Houve dois processos de mutirão: um de alfabetização, incluindo as escolas e os Círculos de Cultura e Aprendizagem; e outro de formação de segundo grau e formação pedagógica para capacitar os professores. Ao longo do tempo, 
a educação foi-se tornando uma política pública reforçada, para a qual se destinavam mais de 50\% dos recursos municipais (ICAPUÍ, 2002).

Investiu-se na capacitação dos professores e profissionais do ensino, primeiramente na formação de ensino médio dos professores, passando então para uma formação de magistério que, em 1989, se consolidou por meio da criação do $2^{\circ}$ grau científico. Posteriormente foi elaborado um convênio com a Universidade Estadual do Ceará (UECE), garantindo cursos de pós-graduação para professores ${ }^{3}$.

Ao longo dos 25 anos dos projetos educacionais, houve diversas alterações no perfil do município. Consolidando-se os dados hoje, nota-se evolução no que tange a alguns aspectos da educação municipal. 0 municipio conta atualmente com uma rede de 20 escolas e 2 creches. Os dados do censo de 2002 apontam a existência de 4.793 alunos matriculados nas escolas (Gráfico 1).

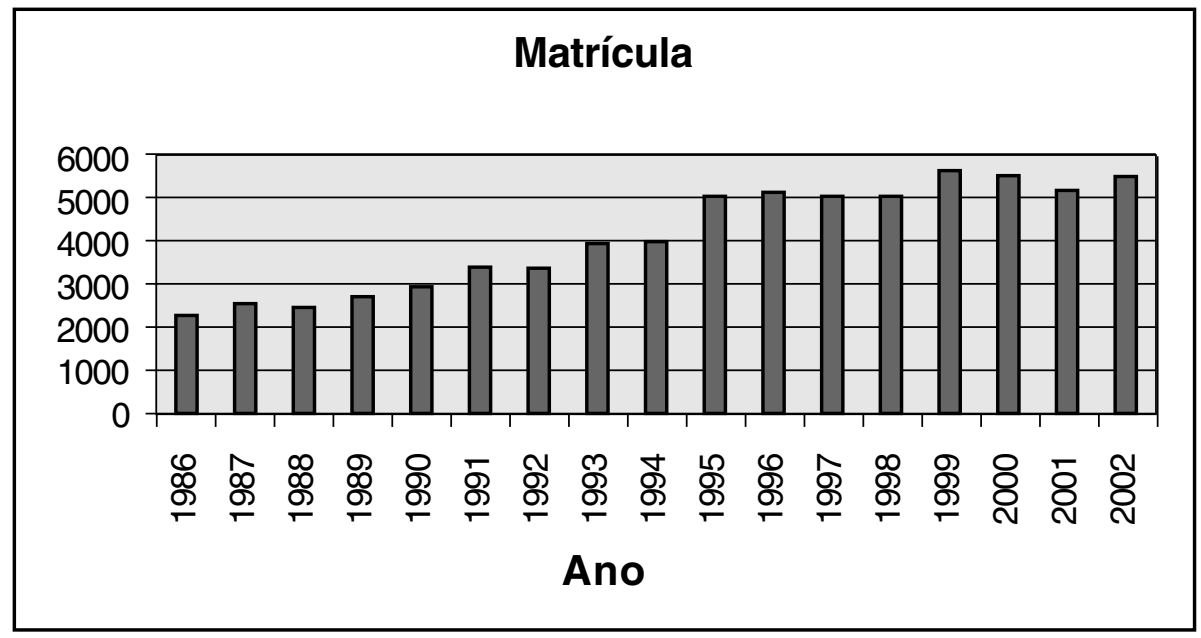

Gráfico 1 - Número de alunos matriculados.

Fonte: Lotta e Martins (2003).

Quanto à taxa de analfabetismo, os dados do IBGE apresentam taxa de 19\% e no ano de 2002 a taxa de evasão escolar foi de 5,9\%. No que se refere ao índice de conclusão de curso, neste mesmo ano, de 284 alunos matriculados na $8^{2}$ série, $87,32 \%$ conseguiram concluir o ensino fundamental.

Existem no município várias atividades ligadas à cultura e ao desporto, havendo 116 núcleos culturais com atividades semanais, um centro de memória da cultura popular, uma biblioteca pública, três bibliotecas escolares e três grupos de teatro de

3 Quase 90\% dos professores já haviam concluido esses cursos em 2003. 
rua. Já com relação ao desporto, o município tem dois ginásios poliesportivos, cinco quadras esportivas e escolinhas de esporte 4.0 município continua fornecendo transporte público e gratuito para as crianças de comunidades onde não há escolas, 0 que estimula as crianças a continuarem estudando.

A capacitação dos professores é ainda um processo contínuo. Hoje existe no município o Programa de Estudo Dirigido para o Docente, que conta com uma série de atividades para a capacitação dos professores como forma de educação continuada.

\section{Conclusão}

No presente trabalho buscou-se mostrar que a análise baseada nos conceitos de capital social e na abordagem neoinstitucionalistas de redes sociais pode ser uma alternativa robusta para compreensão e avaliação de políticas de educação no nivel local. 0 objetivo foi apresentar a análise da política municipal de educação demonstrando que tais abordagens compõem um conjunto de alternativas metodológicas possiveis no campo da investigação de políticas públicas locais. Tomamos como estudo de caso a política municipal de universalização do ensino fundamental do município de Icapuí, município reconhecido e premiado por suas ações na área de educação e saúde.

A partir de uma perspectiva histórica, observou-se que a luta pela emancipação do município, que teve início ainda nos anos 1930 e se intensificou nos começo dos anos 1980 com a liderança do grupo de jovens oriundos de uma oligarquia local, conseguiu não apenas conquistar a independência formal do município, como também implementar uma gestão local inovadora e comprometida com a transformação social, contrapondo-se a uma realidade de descaso e abandono, com um projeto de atendimento às demandas sociais. Apropriando-se da atuação de diversos atores e instituições (grupos de jovens, Igreja Católica, associações comunitárias, etc) foi possivel mobilizar capital social acumulado ao longo dos anos e trazer para dentro da gestão (burocracia do Estado) redes sociais que se haviam constituído e fortalecido no processo de emancipação.

Cada um dos três momentos históricos identificados fornecem elementos que foram fundamentais nas diferentes etapas de formação e mobilização do capital social que influenciaram de maneira positiva a formulação e implementação da política pública de educação. Num primeiro momento, o engajamento cívico se dá em torno da mobilização da sociedade em prol de um objetivo comum. Já num segundo momento, quando as redes sociais assumem os quadros da Prefeitura (1986), existe uma mudança e o Estado passa a mobilizar e articular esse capital social como forma de suprir carências básicas da população, principalmente nas áreas de educação e saúde. A partir do histórico de Icapui, pode-se observar que, mesmo em um quadro de adversidades (e.g. financeiras, sociais e econômicas), a estabilidade e a sustentação política decorreram,

$4 \quad$ Dados válidos até 2004 e coletados em 2003 durante a visita de campo. 
também, de um forte engajamento cívico e redes sociais estruturadas que ocupavam os quadros de gestão dando solidez institucional para as ações políticas e administrativas.

No tocante às redes sociais, o objetivo do trabalho não foi detalhar as redes existentes no município, tampouco construí-las, mas sim ressaltar sua existência e sua importância para o desenvolvimento da administração local que engloba a política pública de educação, uma vez que a utilização de redes sociais é um instrumento de análise importante no campo das ciências sociais.

\section{Referências}

ABU-EL-HAJ, J. 0 debate em torno do capital social: uma revisão crítica. BIB, Rio de Janeiro, n. 47, p. 65-79, jan./jul. 1999.

ALMEIDA, M. A. Estudos de gestão: Icapuí x Janduis. Pólis, São Paulo, n. 11, 1993.

BOURDIEU, P. Le capital social. Actes de La Recherche, n. 30, p. 2-3, 1980.

. The forms of capital. In: RICHARDSON, J. (Org.). The handbook of theory and research for the sociology of education. New York: Geernwood, 1985.

COLEMAN, J. The foundations of social theory. Cambridge: Harvard University Press, 1990.

Social capital in the creation of human capital. American Journal of Sociology, Chicago, n. 94, p. 95-120, 1988. Supplement.

COSTA, M. A. N. Sinergia e capital social na construção de políticas sociais: a favela da Mangueira no Rio de Janeiro. Revista de Sociologia e Política, Curitiba, PR, n. 21, p. 147-163, nov. 2003.

DAHL, R. Dilemmas of pluralistic democracy: autonomy versus control. New Haven: Yale University, 1982.

EVANS, P. Embedded autonomy and industrial transformation: political power and social theory. Princeton: Princeton University, 1996a.

Government action, social capital and development: reviewing on sinergy. World Development, Quebec, Canada, v. 24, n. 6, p. 1119-1132, $1996 \mathrm{~b}$.

FREIRE, P. Pedagogia do oprimido. Rio de Janeiro: Paz e Terra, 1987.

GOUVEIA, A. B. Avaliação da politica educacional municipal: em busca de indicadores de efetividade nos âmbitos do acesso, gestão e financiamento. Ensaio: aval. pol. públ. Educ., Rio de Janeiro, v. 17, n. 64, set./dez. 2009. 
ICAPUI (Ceará). Prefeitura. Secretaria da Educação e Cultura. Plano Municipal de Educação: documento interno. Icapuí, 2002. Mimeografado.

LEVI, M. A. Model, a method and a map. In: LICHBACH, M. I.; ZUCKERMAN, A. S. Comparative politics. Cambridge: Cambridge University, 1997.

LOTA, G. S. Saber e poder: agentes comunitários de saúde aproximando saberes locais e políticas públicas. Dissertação (Mestrado em Administração Pública e Governo) - Fundação Getúlio Vargas, São Paulo, 2006.

LOTTA, G. S.; MARTINS, R. D. A. Estudo da continuidade dos projetos educacionais no Município de Icapuí. Cadernos de Gestão, São Paulo, v. 26, p. 1-57, jun. 2003.

MARQUES, E. C. L. Os mecanismos relacionais. Rev. bras. Ci. Soc., São Paulo, v. 22, n. 64, jun. 2007.

Redes sociais e instituições na construção do estado e da sua

permeabilidade. Revista bras. Ci. Soc., São Paulo, v. 14, n. 41, out. 1999.

. As redes sociais importam para a pobreza urbana?. Dados, Rio de Janeiro, v. 52, n. 2, jun. 2009.

Redes sociais, instituições e atores políticos no Governo da Cidade de São Paulo. São Paulo: Ed. Anablume: FAPESP, 2003.

MARX, K. 18 de Brumario e Cartas a Kungelman. Rio de Janeiro: Ed. Paz e Terra, 1969.

OLSON, M. A lógica da ação coletiva: os benefícios públicos e uma teoria dos grupos sociais. São Paulo: Ed. EDUSP, 1999.

POULANTZAS, N. (Org.) Estado em crise. Rio de Janeiro: Graal, 1977.

PUTNAM, R. Comunidade e democracia: a experiência da Itália moderna. Rio de Janeiro: Ed. FGV, 1996.

Making democracy work: civic traditions in Modern Italy. Princeton: Princeton University Press, 1993.

SANTOS, F. S. Capital social: vários conceitos, um só problema. Dissertação (Mestrado em Administração Pública e Governo) - Fundação Getúlio Vargas, São Paulo, 2003.

TROTTER, R. T. Friends, relatives and relevant others: conducting ethnographic network studies. In: SCHENSUL, J. J. et al. (Org.). Mapping social networks, spatial data, and hidden populations. London: Altamira, 1999.

Recebido em: 04/01/2010

Aceito para publicação em: 06/10/2010 